\title{
UJI KORELASI DENGAN METODE ANALISIS KORELASI KANONIK
}

\author{
Ai Nurhayati ${ }^{1}$, Angling Sugiatna ${ }^{2}$ \\ Program Studi Teknik Industri ${ }^{1,2}$ \\ Sekolah Tinggi Teknologi Bandung ${ }^{1,2}$ \\ ai.nurhayati@sttbandung.ac.id ${ }^{1}$, angling@sttbandung.ac.id ${ }^{2}$
}

\begin{abstract}
Abstrak
Pada saat pandemi covid ini tentu berdampak pada stabilitas ekonomi yang menyebabkan banyaknya pemutusan hubungan kerja sehingga berpengaruh pada jumlah pengangguran di dunia internasional. Variabel yang memengaruhi jumlah pengangguran terdiri atas faktor luar dan faktor individu. Hal yang paling berpengaruh dalam menentukan nasib adalah faktor individu, oleh karena itu pada penelitian ini hanya fokus pada faktor individu saja. Penelitian ini hanya dibatasi untuk mahasiswa yang baru lulus dan berada di pulau Jawa saja. Faktor dari dalam diri mahasiswa sangat berkaitan erat dengan tingkat manajemen waktu. Dalam batasan penelitian ini hanya akan ditinjau dari sisi kebiasaan para mahasiswa dalam mengelola waktunya sehari-hari. Ada beberapa permasalahan yang berkaitan dengan masalah pengangguran yang akan dicarikan solusinya dalam penelitian ini. Permasalahannya adalah apakah tingkat pengangguran berkaitan erat dengan faktor kebiasaan sehari-hari mahasiswa. Variabel-variabel yang diteliti adalah tingkat pengelolaan waktu. Variabel independen terdiri atas variabel lama belajar sendiri dan variabel lama akses internet yang bertema ilmu pengetahuan. Variabel dependen terdiri atas variabel lama lulus kuliah dan variabel lama menganggur. Masalah yang akan diselesaikan adalah berapa besar korelasi antara variabel independen dengan variabel dependen.

Tujuan dari penelitian ini adalah untuk mengetahui berapa besar korelasi antara dua variabel independen: lama belajar sendiri dan lama akses internet ilmu pengetahuan per hari terhadap dua variabel dependen: lama lulus dan lama menganggur. Pendekatan metode yang digunakan di dalam penelitian ini adalah metode analisis multivariat yaitu metode analisis korelasi kanonik. Hasil dari penelitian ini adalah nilai korelasi antara variabel lama lulus terhadap variabel lama belajar sendiri sebesar 0,99994 dan nilai korelasi antara variabel lama menganggur terhadap variabel lama akses internet bertema ilmu pengetahuan sebesar 0,95384. Kesimpulan dari penelitian ini adalah semakin banyak meluangkan waktu untuk belajar mandiri dan semakin sering akses internet bertema ilmu pengetahuan, maka semakin cepat lulus kuliah dan semakin sebentar waktu menganggur atau mudah untuk mendapatkan pekerjaan. Kesimpulannya adalah semakin pintar dalam mengelola waktu sehari-hari, maka semakin cepat untuk menggapai tujuan yang diinginkan.
\end{abstract}

Kata kunci : Analisis korelasi kanonik, korelasi, multivariat, variabel.

\section{Abstract}

At the time of the covid pandemic, it certainly had an impact on economic stability which led to many layoffs, thus affecting the number of unemployed in the international world. Variables that affect the number of unemployed consist of external factors and individual factors. The most influential thing in determining fate is individual factors, therefore in this study only focus on individual factors. This research is only limited to students who have just graduated and are on the island of Java. Factors from within students are closely related to the level of time management. Within the limits of this research, it will only be reviewed from the side of the students' habits in managing their daily time. There are several problems related to the problem of unemployment that will be solved in this study. The problem is whether the unemployment rate is closely related to the factors of students' daily habits. The variables studied were the level of time management. The independent variable consists of the length of self-study and the length of internet access with the theme of science. The dependent variable consists of the variable length of graduation from college and the variable length of unemployment. The problem to be solved is how big is the correlation between the independent variable and the dependent variable.

The purpose of this study was to find out how big the correlation between two independent variables: length of self-study and length of internet access to science per day on the two dependent variables: length of graduation and length of unemployment. The method approach used in this research is the multivariate analysis method, namely the canonical correlation analysis method. The results of this study are the correlation value between the variable length of graduation with the variable length of study alone is 0.99994 and the correlation value between the variable length of unemployment and the variable duration of internet access with the theme of science is 0.95384 . The conclusion of this study is that the more time you spend for independent study and the more often you access the internet with the theme of science, the sooner you will graduate from college and the less time you will be unemployed or it will be easier to get a job. The conclusion is that the smarter you are in managing your daily time, the faster you will reach your desired goals.

Keywords : Canonical correlation analysis, correlation, multivariate, variable.

\section{PENDAHULUAN}

Dokumen ini adalah template. Pendahuluan memuat latar belakang masalah, fokus masalah yang akan diselesaikan, metoda atau pendekatan penyelesaian, serta hasil yang diharapkan. Badan Pusat Statistik (BPS) mencatat, jumlah pengangguran di Indonesia mencapai 8,75 juta orang pada Februari 2021. Jumlah tersebut meningkat 26,26\% dibandingkan periode yang sama tahun lalu sebesar 6,93 juta orang. Adapun, tingkat pengangguran terbuka (TPT) di Indonesia mencapai 6,26\% pada Februari 2021. TPT tersebut naik 1,32\% poin dibandingkan Februari 2020 yang sebesar 4,99\%. TPT tertinggi pada Februari 2021 tercatat berada di perkotaan mencapai 8\%. Sementara, TPT di perdesaan sebesar $4,11 \%[1]$. 


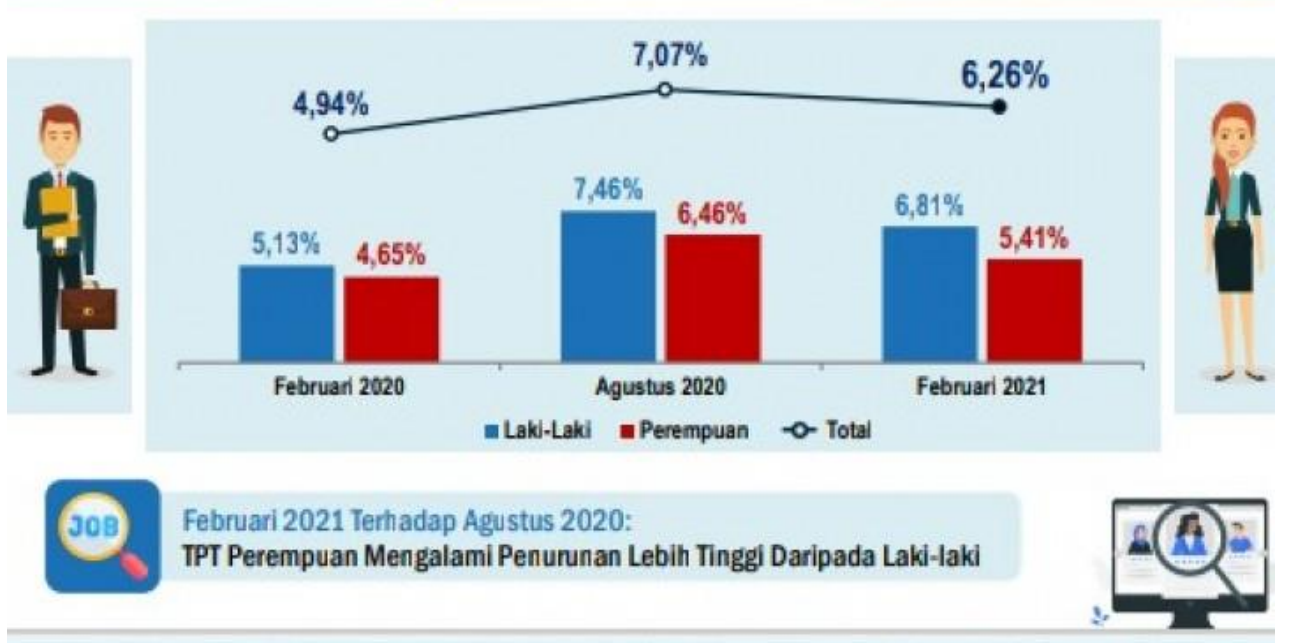

Gambar 1 Histogram Tingkat Pengangguran [2]

Pada Gambar 1 dapat terlihat histogram persentase tingkat pengangguran terbuka antara laki-laki dan perempuan mulai dari tahun 2020 sampai tahun 2021.

\section{TINJAUAN PUSTAKA}

Analisis multivariat adalah semua teknik statistik secara berkesinambungan menganalisis banyak pengukuran pada individu-individu atau objek-objek yang diselidiki. Jadi, sebuah analisis berkesinambungan lebih dari dua variabel bisa dipertimbangkan sebagai analisis multivariat [3]. Banyak teknik multivariat merupakan perluasan dari analisis univariat (analisis distribusi variabel tunggal) dan analisis bivariat (klasifikasi-silang, korelasi, anova dan regresi sederhana yang digunakan untuk analisa dua variabel) [3].

Pendekatan yang digunakan melalui uji statistika untuk mengukur keeratan hubungan antara dua variabel disebut analisis korelasi (correlation analysis) [4].

Tujuan analisis kanonik adalah untuk menghubungkan secara bersamaan beberapa variabel dependen metrik dan beberapa variabel independen metrik [5].

Rumus korelasi kanonik [6]:

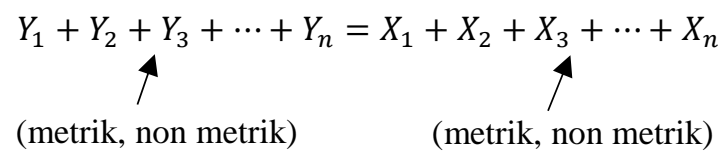

\section{HASIL ANALISIS DATA}

Di dalam penelitian ini terdapat dua variabel dependen dan dua variabel independen sehingga terbentuk dua fungsi kanonik yang dapat dilihat pada bagian nomor root. Pada Tabel 1 adalah hasil output dari SPSS yang memperlihatkan angka korelasi kanonik (Canon Cor.) untuk fungsi 1 sebesar 0,99479 dan untuk fungsi 2 sebesar 0,06793.

TABEL I

NILAI EIGEN DAN KORELASI KANONIK

\begin{tabular}{|l|l|l|l|l|l|}
\hline Nomor Root & Nilai Eigen & Pct. & Cum. Pct. & Canon Cor. & Sq. Cor. \\
\hline 1 & 95,1723 & 99,99513 & 99,99513 & 0,99479 & 0,98960 \\
\hline 2 & 0,00464 & 0,00487 & 100 & 0,06793 & 0,00461 \\
\hline
\end{tabular}

TABEL II

ANALISIS REDUKSI DIMENSI

\begin{tabular}{|l|l|l|l|l|l|}
\hline Root & Wilks L. & F & Hypoth. DF & Error DF & Sig. of F \\
\hline 1 TO 2 & 0,01035 & 225,15101 & 4 & 102 & 0 \\
\hline 2 TO 2 & 0,99539 & 0,24105 & 1 & 52 & 0,626 \\
\hline
\end{tabular}


Pada Tabel 2 dapat dilihat pada kolom Sig. of $F$ yang menguji signifikansi fungsi kanonik, tampak untuk fungsi 1 memiliki angka signifikan sebesar 0, sedangkan untuk fungsi 2 memiliki angka signifikan sebesar 0,626. Dari hasil tersebut, tampak bahwa angka signifikan fungsi 1 jauh di bawah 0,05 sehingga fungsi 1 secara individu adalah signifikan dan dapat diproses lebih lanjut. Fungsi 2 memiliki angka signifikan jauh di atas 0,05, maka fungsi 2 secara individu dianggap tidak dapat diproses lebih lanjut.

TABEL III

UJI SIGNIFIKANSI MULTIVARIAT ( $\mathrm{S}=2, \mathrm{M}=-1 / 2, \mathrm{~N}=241 / 2)$

\begin{tabular}{|l|l|l|l|l|l|}
\hline Nama Uji & Nilai & Approx. F & Hypoth. DF & Error DF & Sig. of F \\
\hline Pillais & 0,99422 & 25,70097 & 4 & 104 & 0 \\
\hline Hotellings & 95,17693 & 1189,71168 & 4 & 100 & 0 \\
\hline Wilks & 0,01035 & 225,15101 & 4 & 102 & 0 \\
\hline Roys & 0,9896 & & & & \\
\hline
\end{tabular}

Pada Tabel 3 dapat dilihat proses uji bersama-sama dengan 4 prosedur (Pillais, Hotellings, Wilks, Roys) tampak angka signifikan Sig. of $F$ untuk ketiga prosedur (Pillais, Hotellings, Wilks) semuanya di bawah 0,05 (yaitu nol). Dengan demikian, jika digabung secara bersama-sama, fungsi kanonik 1 dan fungsi kanonik 2 akan signifikan dan dapat diproses lebih lanjut.

Ada perbedaan antara pengujian individu dan bersama (kolektif). Untuk itu, dapat dilihat pada angka korelasi kanonik yang terdapat di Tabel 1, dengan angka:

a. Fungsi korelasi kanonik 1 bernilai 0,99479

b. Fungsi korelasi kanonik 2 bernilai 0,06793

Dengan batas angka 0,5 untuk kekuatan korelasi dua variabel, maka fungsi 2 memiliki nilai korelasi kanonik yang rendah sehingga dapat dikeluarkan pada tahap analisis selanjutnya. Dengan demikian, hanya fungsi 1 yang akan dianalisis lebih lanjut karena selain signifikan secara individu dan bersama-sama, juga memiliki nilai korelasi kanonik yang besar.

Setelah diketahui fungsi kanonik 1 signifikan, tahapan berikutnya adalah melakukan interpretasi terhadap hasil variat kanonik yang terdapat pada fungsi 1 tersebut. Variat kanonik adalah kumpulan dari beberapa variabel yang membentuk suatu variat. Dalam penelitian ini, ada dua variat kanonik yaitu variat kanonik dependen (variabel lama lulus dan variabel lama menganggur) serta variat kanonik independen (variabel lama belajar sendiri dan variabel lama akses internet ilmu pengetahuan). Analisis dari penelitian ini pada prinsipnya ingin mengetahui apakah semua variabel independen dalam variat kanonik tersebut berkaitan erat dengan variat dependen, yang diukur dengan nilai korelasi setiap variabel independen terhadap variatnya.

Pengukuran variat kanonik dapat dilakukan dalam dua tahap, yaitu: bobot kanonik dan kanonik loading.

a. Bobot kanonik

Untuk variat dependen dapat dilihat pada Tabel IV.

TABEL IV

KOEFISIEN KANONIK STANDARD UNTUK VARIABEL DEPENDEN

\begin{tabular}{|l|l|l|}
\hline \multirow{2}{*}{ Variabel } & \multicolumn{2}{|l|}{ Nomor Fungsi } \\
\cline { 2 - 3 } & $\mathbf{1}$ & $\mathbf{2}$ \\
\hline Lama lulus & 1,03575 & $-3,28953$ \\
\hline Lama menganggur & $-0,03742$ & 3,44854 \\
\hline
\end{tabular}

Untuk variat independent dapat dilihat pada Tabel V

TABEL V

KOEFISIEN KANONIK BARIS UNTUK KOVARIAT

\begin{tabular}{|l|l|l|}
\hline \multirow{2}{*}{ Kovariat } & \multicolumn{2}{|l|}{ Nomor Fungsi } \\
\cline { 2 - 3 } & $\mathbf{1}$ & $\mathbf{2}$ \\
\hline Lama belajar sendiri & $-1,44451$ & $-3,57081$ \\
\hline Lama akses internet ilmu pengetahuan & 0,43748 & 6,13402 \\
\hline
\end{tabular}

Pada Tabel IV dengan mengabaikan fungsi 2 (kolom angka ke-2), tampak deretan angka korelasi antara setiap variabel terhadap variatnya. Untuk variabel dependen pada Tabel IV, angka korelasi lama lulus sangat besar $(1,03575)$ karena berada di atas 0,5 , sedangkan angka korelasi lama menganggur kecil $(-0,03742)$ karena berada di bawah 0,5. Untuk variabel independen (kovariat) pada Tabel V, angka korelasi di atas 0,5 hanya ada 1 variabel yaitu lama belajar sendiri. Selain dengan bobot kanonik, interpretasi hasil juga dapat dilakukan dengan melihat besaran kanonik loading. Pada Tabel IV dan Tabel V dapat dilihat bahwa tanda negatif pada variabel lama belajar sendiri dan tanda positif pada variabel lama lulus berarti semakin sedikit waktu untuk belajar sendiri maka semakin lama untuk lulus kuliah.

Pada Tabel IV dan Tabel V dapat dilihat tanda positif pada variabel lama akses internet ilmu pengetahuan dan tanda negatif pada variabel lama menganggur menandakan bahwa semakin banyak menyediakan waktu yang 
lama untuk akses internet ilmu pengetahuan maka semakin sebentar waktu menganggurnya atau semakin cepat dapat kerja.

b. Kanonik loading

Untuk variat dependen dapat dilihat pada Tabel VI.

TABEL VI

KORELASI ANTARA VARIABEL DEPENDEN DAN KANONIK

\begin{tabular}{|l|l|l|}
\hline \multirow{2}{*}{ Variabel } & \multicolumn{2}{|l|}{ Nomor Fungsi } \\
\cline { 2 - 3 } & $\mathbf{1}$ & $\mathbf{2}$ \\
\hline Lama lulus & 0,99994 & 0,01085 \\
\hline Lama menganggur & 0,95384 & 0,30033 \\
\hline
\end{tabular}

Untuk variat independen dapat dilihat pada Tabel VII.

TABEL VII

KORELASI ANTARA VARIABEL KANONIK DAN KOVARIAT

\begin{tabular}{|l|l|l|}
\hline \multirow{2}{*}{ Kovariat } & \multicolumn{2}{|l|}{ Can. Var. } \\
\cline { 2 - 3 } & $\mathbf{1}$ & $\mathbf{2}$ \\
\hline Lama belajar & $-0,99747$ & 0,07114 \\
\hline Lama akses internet ilmu pengetahuan & $-0,92702$ & 0,37501 \\
\hline
\end{tabular}

Pada Tabel VI dengan mengabaikan fungsi 2 (kolom angka ke-2), tampak deretan angka kanonik loading antara setiap variabel terhadap variatnya (fungsi). Untuk variabel dependen pada Tabel VI, dua angka kanonik loadings sama besarnya karena di atas 0,5 yaitu 0,99994 dan 0,95384. Untuk variabel independen (kovariat) pada Tabel VII, angka korelasi sangat besar di atas 0,5 untuk variabel lama belajar dan variabel lama akses internet ilmu pengetahuan. Pada Tabel VI dan Tabel VII dapat terlihat tanda negatif pada variabel lama belajar dan tanda positif pada variabel lama lulus. Artinya, semakin sedikit atau semakin sebentar belajar sendiri maka semakin bertambah lama waktu untuk lulus kuliah. Pada Tabel VI dan Tabel VII dapat terlihat tanda negatif pada variabel lama akses internet ilmu pengetahuan dan tanda positif pada variabel lama menganggur. Artinya, semakin sedikit waktu atau semakin sebentar waktu untuk akses internet ilmu pengetahuan, maka semakin bertambah lama waktu untuk menganggur atau lama cari kerja.

\section{KESIMPULAN}

Berdasarkan hasil penelitian ini, terutama hasil output bobot kanonik dan kanonik loadings, dapat ditarik kesimpulan sebagai berikut:

1. Terdapat hubungan yang signifikan antara variat dependen dengan variat independen. Artinya lama belajar mandiri seseorang dan lama akses internet ilmu pengetahuan ternyata berkorelasi secara bersama-sama dengan lama lulus kuliah dan lama menganggur (dua variabel independen).

2. Dari dua variabel independen lama belajar mandiri dan lama akses internet ilmu pengetahuan berhubungan erat dengan variabel dependen.

3. Tanda negatif untuk variabel lama belajar dan lama akses internet dan tanda positif untuk variabel lama lulus dan lama menganggur. Artinya, semakin sedikit waktu belajar mandiri dan semakin sebentar akses internet ilmu pengetahuan, maka semakin bertambah lama waktu untuk lulus kuliah dan semakin lama waktu menganggur atau susah dapat kerja.

Kesimpulan akhir dari penelitian ini adalah para mahasiswa sebaiknya meluangkan waktu untuk belajar mandiri, mencoba memahami sendiri mengenai materi kuliah yang sudah disampaikan oleh para dosen dan bertanya kepada dosen bersangkutan apabila kurang faham agar segera lulus kuliah. Kedua, para mahasiswa ketika sedang menyusun tugas akhir atau skripsi, sebaiknya banyak berselancar di internet yang berkaitan dengan pengetahuan mengenai lapangan pekerjaan agar sesudah wisuda dapat segera memperoleh pekerjaan yang diminati.

\section{REFERENSI}

[1] https://databoks.katadata.co.id/datapublish/2021/05/05/jumlah-pengangguran-capai-875-juta-orang-per-februari-2021

[2] https://m.suarakarya.id/detail/132463/BPS-Tingkat-Pengangguran-Terbuka-Februari-626-Persen

[3] A. Nurhayati, Dasar-dasar Analisis Multivariat. Bandung, Indonesia: FBM Solusindo, 2019.

[4] Miftahuddin, A. Pratama, I. Setiawan, "Analisis Hubungan Antara Kelembaban Relatif Dengan Beberapa Variabel Iklim Dengan Pendekatan Korelasi Pearson Di Samudera Hindia,” Jurnal Siger Matematika, vol. 2, no. 1, Maret 2021.

[5] A. Nurhayati dan A. Sugiatna, Analisis Data Statistik. Bandung, Indonesia: FBM Solusindo, 2020.

[6] J. F. Hair, W. C. Black, B. J. Babin, and R. E. Anderson, Multivariate Data Analysis (MVDA), 7th ed. London: Pearson, 2014. 